\title{
REDUÇÃO DA DESCLASSIFICAÇÃO DE CORRIDAS POR TEORES DE FÓSFORO*
}

Denise Freire Duarte ${ }^{1}$

Lívia Lopes de Oliveira Goulart ${ }^{2}$

\section{Resumo}

Desclassificações de corridas por elementos fora da faixa de especificação do tipo do aço que está sendo produzido impactam negativamente nos indicadores da empresa. É esforço contínuo os projetos de melhoria e ações implantadas para a redução dessas desclassificações. Quando uma corrida é desclassificada, há um custo para refazer a corrida perdida, ocorre um processo de reclassificação que fica em estoque aguardando aplicação, perde-se tempo e pontualidade na produção entre outros impactos. Portanto identificar a causa raiz do problema e atuar em ações efetivas e bem implantadas são as chaves para a resolução do problema e melhoramento do processo. O fósforo é um elemento que deve ser controlado pois é item de norma para atendimento às especificações pois impactam na fragilização do material. Este trabalho mostra a análise realizada na busca da causa raiz das ocorrências das desclassificações de fósforo.

Palavras-chave: Não-conformidade; Fósforo; Gusa; Silício.

\section{REDUCING THE DECLASSIFICATION OF HEAT BY PHOSPHORUS CONTENT}

\begin{abstract}
Declassification of heats by elements outside the specification range of the type of steel being produced has a negative impact on the company's indicators. It is a continuous effort to improve and implement actions to reduce these declassifications. When a heat is disqualified, there is a cost to redo the lost heat, a process of reclassification takes place that is in stock awaiting application, time is lost and punctuality in production among other impacts. Therefore identifying the root cause of the problem and acting on effective and well-implemented actions are the keys to solve the problem and improving the process. Phosphorus is an element that must be controlled because it is a standard item to meet the specifications because it impacts the embrittlement of the material. This work shows the analysis carried out in the search for the root cause of the occurrences of phosphorus declassifications.
\end{abstract}

Keywords: Non-conformity; Phosphor; Pig iron; Silicon.

1 Engenharia de Produção, Bacharel, Engenheiro de Qualidade, Aciaria Elétrica, VSBM, Barra Mansa, Rio de Janeiro, Brasil.

2 Engenharia Metalúrgica, Bacharel, Engenheira de Processos, Aciaria Elétrica, VSBM, Barra Mansa, Rio de Janeiro, Brasil. 


\section{INTRODUÇÃO}

O Fósforo é um elemento que quando se apresenta acima da especificação causa danos no material laminado, causa fragilização impactando a qualidade final e trazendo impactos para os laminadores, por isso é de extrema importância que o aço produzido na Aciaria tenha o controle dos níveis de Fósforo em sua composição química. Cada tipo de aço tem sua aplicação e finalidade específica e isto exige que sua composição química esteja dentro dos parâmetros da norma para atender a aplicação. Nos aços-liga, o fósforo é especificado com 0,04\% no máximo em alguns casos e em outros, $0,025 \%$ máximo. Não possui esse elemento tendência a formar carbonetos, mas dissolve-se na ferrita, endurecendo-a e aumentando o tamanho de grão do material, ocasionando a "fragilidade a frio", representada por baixa resistência ao choque ou baixa tenacidade. Essa influência é tanto mais séria, quanto mais alto o teor de carbono do aço. Vários fatores podem ser responsáveis para a ocorrência de corridas com teor de Fósforo acima das especificações. Podemos ter influência na sucata e durante o processo do FEA. Este trabalho se deu pela ocorrência crônica no mês de Janeiro de 2016 devido a tonelada de material que apresentou fósforo acima da especificação.

Foram analisadas as variáveis que impactam no surgimento do problema mas um outro fator foi a causa principal e será apresentado no decorrer deste trabalho.

\section{MATERIAIS E MÉTODOS}

No mês de Janeiro de 2016 ocorreram 22 corridas totalizando 1094t de não conformidade por ocorrência de Fósforo alto, um número bastante expressivo e impactante no Índice de Qualidade da Aciaria. Este número foi $238 \%$ acima comparado à média mensal do ano anterior. A forte incidência nos mostrou que o processo estava anormal e que algo deveria ser feito de imediato. $O$ gráfico de Pareto mostrou que era o principal problema na qualidade.

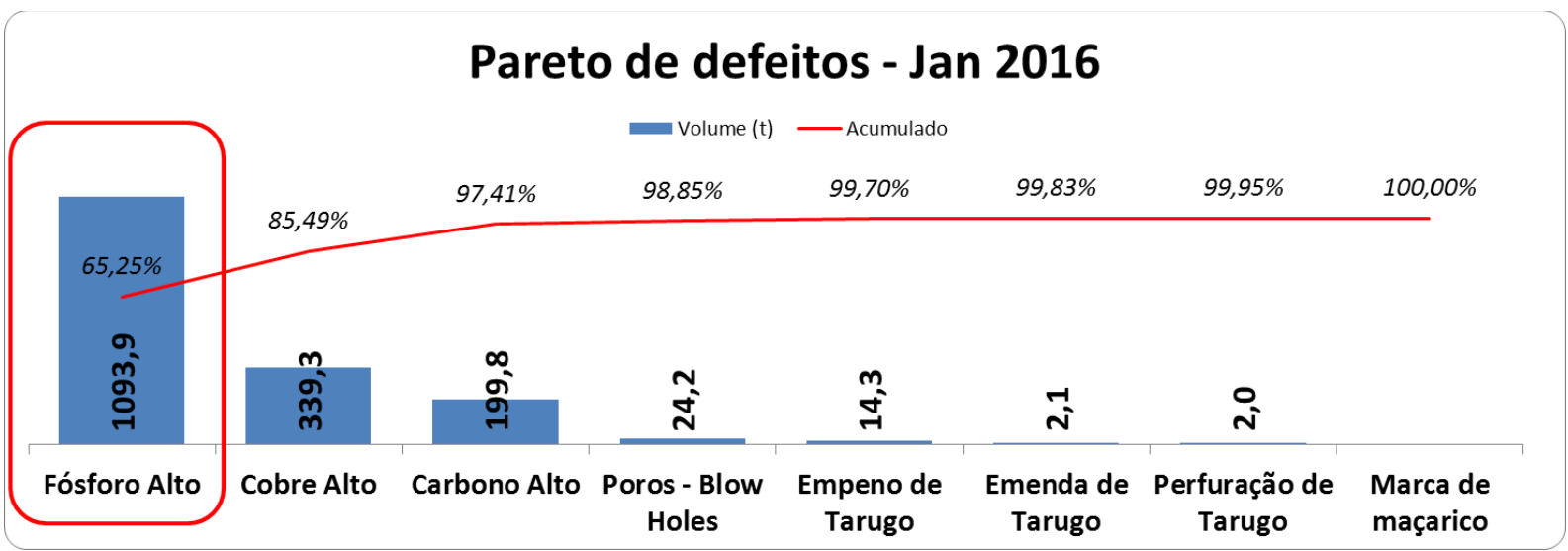

Gráfico 1. Pareto dos defeitos

A primeira ação foi investigar se as variáveis do processo estavam dentro dos parâmetros corretos. Após uma reunião de Brainstorming com operação e suporte técnico foi investigado as seguintes variáveis: Adição de Cal (para ver se houve falta de adição ou adição no momento incorreto), \%C alto e PPM de oxigênio<400 (Pela questão da desoxidação e afinidade do oxigênio primeiramente ao $C$ do que ao $P$ ), Temperatura de vazamento excessiva (fazendo a reversão ao banho) e Passagem de Escória (reversão para o banho). De todas as corridas que apresentaram \%P fósforo 
alto, não foi identificado uma causa comum para justificar a anormalidade no processo, de início foram encontrados fatores variados que somados à causa principal (até então) não encontrada contribuíram para a ocorrência. Após isto o passo dado foi o de investigar a matéria-prima, no caso o ferro-gusa. Identificou-se nas análises do fornecedor que o \%Si no gusa estava além do permitido para o processo da Aciaria. Em um trabalho anterior identificou-se que \%Si até 0,60 seria 0 valor limite para 0 gusa. Houveram cargas de gusa que abasteceram a Aciaria com 1,48\% de Silício. A partir desta descoberta foi criado um plano de ação para tratar a causa fundamental bem como as causas secundárias. Abaixo na Figura 1 segue o Diagrama de Ellingham que explica as reações de oxidação dos elementos. Quanto mais baixa a curva, quer dizer que menor é a energia livre de Gibs para ocorrer a reação, ou seja, mais fácil ocorrer a reação, já que a natureza sempre procura um estado de menor energia. Sendo assim, a reação de oxidação de Si que tem a curva de menor energia, faz com que todo o Si seja oxidado primeiro antes do $\mathrm{C}$ e antes ainda do $\mathrm{P}$ que é o último a ser oxidado nessas condições. Logo, para uma mesma quantidade de $\mathrm{O} 2$ setado no programa químico do FEA e com maior quantidade de Si proveniente do gusa, mais oxigênio é gasto para formação da SiO2, "faltando" então O2 para transformar o P do banho em P2O5, fazendo as corridas saírem fora de faixa com P alto.

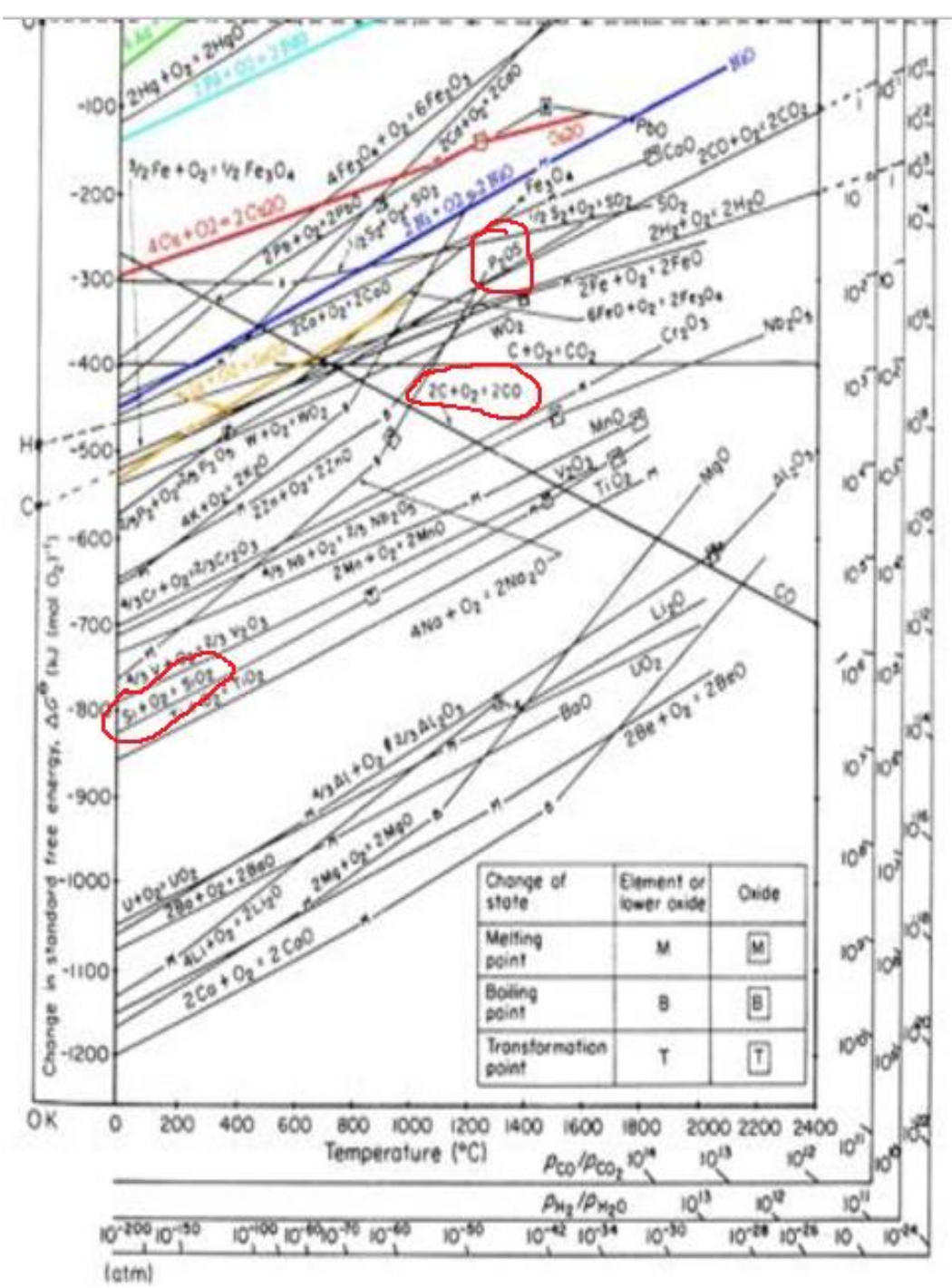

Figura 1. Diagrama de Ellingham 


\begin{tabular}{|c|c|c|}
\hline \multicolumn{2}{|c|}{ NOTA FISCAL No: $\quad 118894$} & QUANTIDADE: 28.000 \\
\hline \multicolumn{3}{|l|}{ LOTE No: AI-L4 } \\
\hline \multicolumn{2}{|c|}{ FERRO GUSA ACIARIA } & \\
\hline Elementos & $\begin{array}{c}\text { Material } \\
\text { Especificado na } \\
\text { Norma } \\
\end{array}$ & $\begin{array}{l}\text { Valores mèdios } \\
\text { Metalsider }\end{array}$ \\
\hline Carbono (C) & 3,00 A 5,00 & 4.00 \\
\hline Enxofre (S) & $0.050 \% \mathrm{MAX}$ & 00210 \\
\hline Silicio ( $\mathrm{Si}$ ) & 0,00 A 5,00 & 1.48 \\
\hline Manganês ( Mn ) & 1,00 MAX\% & 0.29 \\
\hline Fósforo (P) & $0.15 \% \mathrm{MAX}$ & 0.097 \\
\hline
\end{tabular}

Figura 2. Teor de Silício encontrado em um dos lotes de gusa.

\section{RESULTADOS E DISCUSSÃO}

A implementação do plano de ação envolveu as áreas do pátio de sucata e fornos elétricos onde as causas foram identificadas. Os operadores tomaram conhecimento do problema e das causas que influenciaram. Foram retreinados nos padrões que necessitaram ser revisados. Quando implementado as ações para a causa principal o resultado foi instantâneo. O gusa foi separado em baias pelo \%Si que apresentava e a carga de sucata abastecida com gusa no FEA foi dosada. Outras ações como contato com fornecedor e revisão do padrão de especificação também foram realizadas.

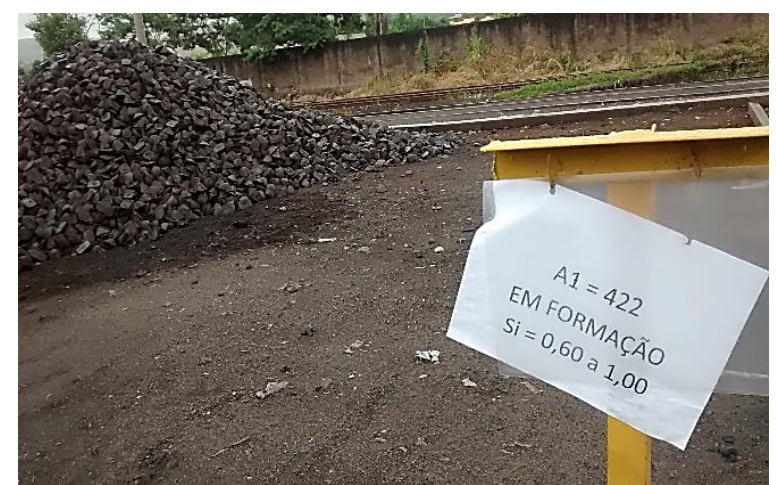

Imagem 1: Separação do gusa pelo \%Si 


\section{QPH FÓSFORO FORA DA ESPECIFICAÇÃO}

国 Volume médio mensal $(\mathrm{t}) \quad$ Volume $(\mathrm{t})$

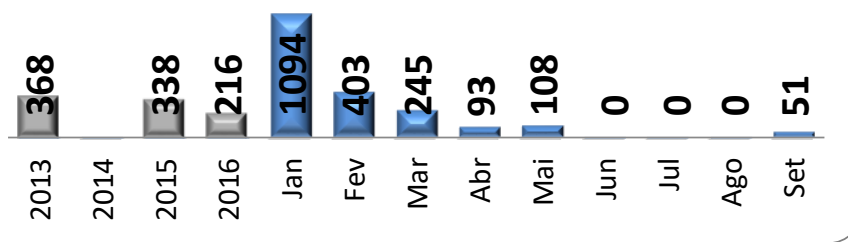

Gráfico 2. Evolução da incidência de \%P acima da especificação

Quando o plano de ação foi efetivamente concluído, conseguimos ter redução significativa da ocorrência do problema nos meses seguintes. Em Junho, Julho e Agosto de 2016 obteve-se a redução de 100\% das corridas com \%P acima da especificação. Diversas ações foram tomadas, porém a efetiva foi o tratamento do gusa pelo \%Si no pátio de sucatas.

\section{CONCLUSÃO}

O presente trabalho mostrou que uma análise bem feita e realizada em contato com a operação traz inúmeros benefícios, entre eles a velocidade de resposta para resolver o problema. Nos trouxe também grande aprendizado pois somente poucas pessoas já haviam tido experiência com esse problema no passado e puderam contribuir. Hoje, a operação do pátio de sucata mantém a atividade de verificação das cargas de gusa pelo bom resultado que o trabalho trouxe, criou-se valor, viu-se a importância da separação das pilhas para as suas entregas. Estar próximo da operação é fator crucial para o resultado do trabalho do Engenheiro de Processo, pois é nela que está a capacidade de fazer o resultado.

\section{REFERÊNCIAS}

1 CHIAVERINI, V.; Aços e Ferros Fundidos. 7ª̣ Edição. São Paulo, ABM; 2008. 